\title{
STUDY OF CORROSION OF REINFORCED STEEL BARS IN RECYCLED AGGREGATE CONCRETE WITH FLY ASH
}

\author{
C Ravi Kumar Reddy ${ }^{1}$, CH Hema Sindhusha ${ }^{2}$, G Hymavathi ${ }^{3}$, N Ramyasri ${ }^{4}$ \\ ${ }^{1}$ Professor, Civil Engineering Department, $K$ L University, A P, India \\ ${ }^{2} P G$ Scholar, Civil Engineering Department, $K$ L University, A P, India \\ ${ }^{3} P G$ Scholars, Civil Engineering Department, $K$ L University, A $P$, India \\ ${ }^{4} P G$ Scholar, Civil Engineering Department, K L University, A P, India
}

\begin{abstract}
Large number of old buildings and other structures have reached the end of their service life and are being demolished, resulting in generation of demolished concrete. Some of this concrete wastes are used as backfill material and much being sent to landfills. Recycling concrete by using it as replacement to new aggregate in concrete could reduce concrete waste and conserve natural source of aggregate. Recycled aggregate reduce cost savings. Use of recycled aggregate in concrete can be useful for reducing dumping problems and scarcity of virgin aggregates. In present study, in addition to the recycled aggregate, fly ash has been used to study the durability properties of recycled aggregate concrete. Properties of Recycled Aggregate Concrete were compared with Conventional Concrete with varying fly ash content. While the corrosion protection of the reinforcing steel in no substitute for design and the placement of good quality concrete, it does provide for a viable and economical extension of structural integrity and service life in the day to day and practical environment in which concrete structures are constructed. The process of corrosion, its forms of attack and consequent deterioration of reinforcement concrete structures is well understood and documented. This paper explores the economic and practical benefits offered by the application of recycled aggregate concrete and advantages of recycled aggregate concrete with and without admixtures.
\end{abstract}

Keywords: Recycled aggregate, Fly ash, Concrete, and corrosion in steel

\section{INTRODUCTION}

Recycled aggregates are the materials for the future. Recycled concrete aggregate (RCA) is defined as a minimum of $95 \%$ crushed concrete, and recycled aggregate (RA) is defined as maximum of $100 \%$ crushed masonry, as per concrete product standard BS 8500-2. Recycled aggregates are therefore not the same as "recovered" aggregates, which are obtained by washing the cement paste out of fresh concrete and returning aggregates to stockpile. Fly ash is residue left from burning coal, which is collected on an electrostatic precipitator or in a bag house. It mixes with flue gases that result when powdered coal is used to produce electric power. The most important Benefit of flyash is reduced permeability to water and aggressive chemicals. Properly cured concrete made with fly ash creates a denser product because the sizes of the pores are reduced. This increases strength and reduces permeability. Berndt [1] has reported that the recycled concrete was sieved into three size fractions $6.35-12.7 \mathrm{~mm}, 12.7-19 \mathrm{~mm}$ and 19-25.4 mm. Yang and Wang [2] have studied the diffusion characteristic of concrete with mineral admixtures between salt ponding test and accelerated chloride migration test. Chakradhara Rao [3] has studied the properties of recycled aggregate concrete like water absorption, specific gravity, compressive strength, density, porosity and micro hardness and fount the result that the compressive strength of recycled aggregate concrete was found to be lower than that of corresponding normal concrete after 28 days of curing. The porous interfacial transition zone in recycled aggregate concrete may be attributed to the higher absorption capacity of recycled aggregates. Yang et al [4] have reported that Physical characteristics of RCA had 3 to $10 \%$ lower density and 3 to 5 times higher absorption than BNA in the saturated surface dry state, reflecting the porosity of cement paste surrounding the RCA. Limbachiya et al [5] have reported that the original concrete types selected to produce coarse RCA were clean and free from detrimental levels of chemical impurities and other harmful constituents. Parekh and Modhera [6] have found that control of the free water to cement ratio $(w / c)$ and the workability of fresh concrete is difficult and results in a higher shrinkage and creep of the hardened concrete when compared with the concrete prepared with the natural aggregates. The extent to which the properties of concrete are affected by the use of Recycled aggregate depends on the water absorption, crushing value and soundness of the aggregate. Zuhair [7] has investigated the polarization methods on recycled aggregate concrete for corrosion and rate measurements.

\section{EXPERIMENTAL INVESTIGATION}

\subsection{Mix Proportioning}

Ordinary Portland cement - 43 Grade JP Cement and locally available river sand have been used in the present study. A mix was designed using Indian Standard Code of Practice with conventional materials for a characteristic strength of $30 \mathrm{MPa}$. The mix proportion is arrived at 1: 2.15: 2.86 with 
water cement ratio as 0.45 and cement content of $380 \mathrm{~kg} / \mathrm{m}^{3}$ for mixes with recycled aggregate the same proportions are adopted with minor changes on account of variation of their bulk density and specific gravity.

\subsection{Corrosion Studies}

There are several tests available for conducting corrosion studies on reinforcing bars. Initially the rods were treated in diluted $\mathrm{HCl}$ solution for removing initial corrosion present around it. After keeping in solution for $24 \mathrm{hrs}$, the rods were gently wiped and cleaned with a dry cloth and initial weights were noted before placing them in molds. Following are the experiments conducted for corrosion studies on different samples with varying proportions of fly ash replacing cement in conventional concrete and recycled aggregate concrete.

- $\quad$ Salt Ponding Test

- Linear Polarization Resistance Test

- Impressed Voltage Test

- Weight Loss Test

\subsection{Salt Ponding Test}

The salt ponding test involves a combination of absorption, diffusion, and wicking (due to drying from the bottom side). The concrete cubes were casted as a part of five different sets (15 samples) for normal aggregate concrete (NAC) and also for concrete with $100 \%$ Recycled aggregate cement replaced with $0 \%, 10 \%, 20 \%$ and $30 \%$ of fly ash (RAC-0, RAC-10, RAC-20 and RAC-30). Each specimen consists of two $10 \mathrm{~mm}$ dia reinforced bars with a length of $100 \mathrm{~mm}$ embedded inside at a clear cover of $30 \mathrm{~mm}$ from inside. Before inserting rods, each rod should be sealed with sealant to a height of $15 \mathrm{~mm}$ above and below the center as shown in Fig -1 .

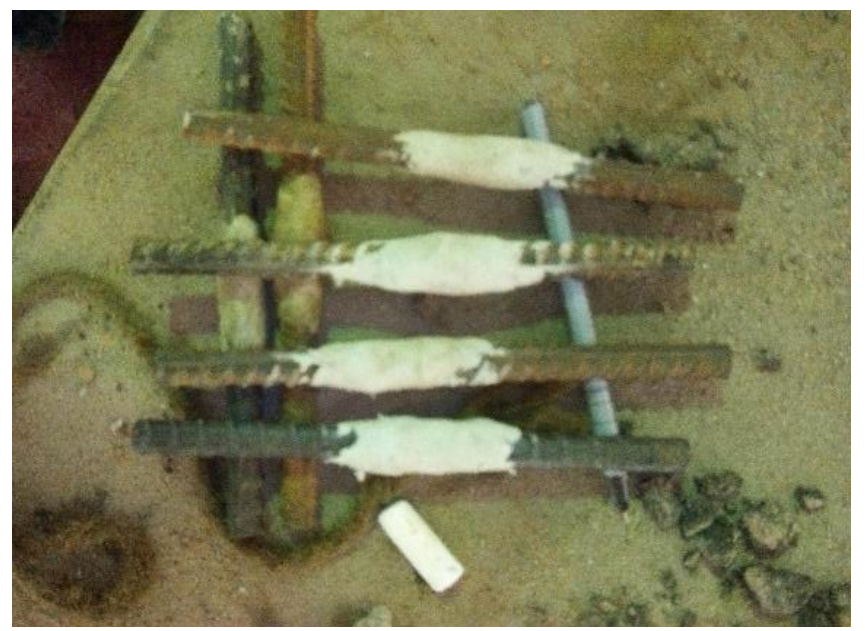

Fig -1: Sealing Reinforcing bars

The specimens were cured for 28 days in water and air-dried for one day. Bunds were constructed over the cubes and were sealed perfectly such that there is no leakage. Bunds have to be constructed to a height of $150 \mathrm{~mm}$ for ponding $\mathrm{NaCl}$ solution of $5 \%$ concentration to a height of $100 \mathrm{~mm}$ and should be maintained. Connections should be given such that one rod is connected to positive terminal and other to negative terminal as shown in Fig -2 .

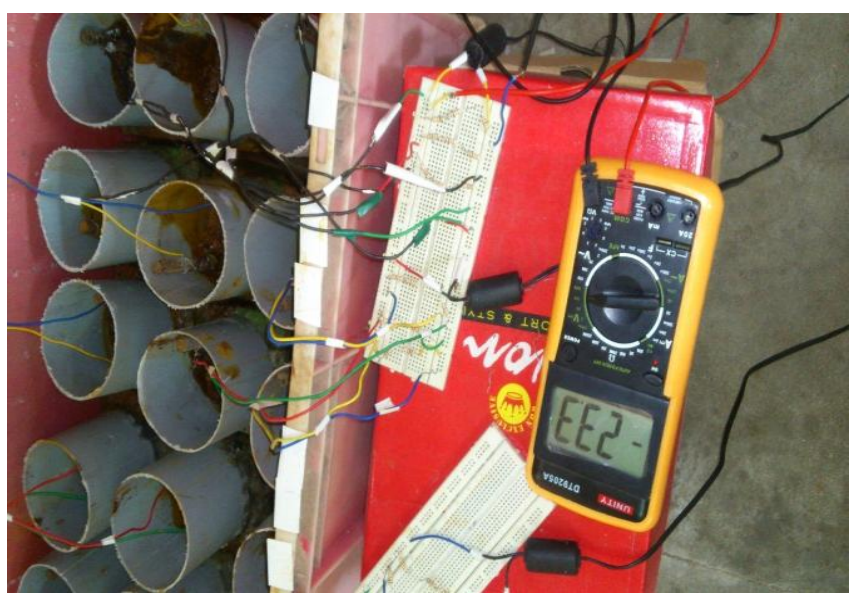

Fig -2: Circuit connections and Voltage regulation

A constant voltage of $23 \mathrm{~V}$ is supplied to all specimens and variation in current and resistance were measured using a multimeter. For measuring voltage, the multimeter is adjusted to DC-VOLTAGE and probes were connected in parallel to the connection. And for measuring current, it should be connected in series. For measuring resistance a standard reference calomel electrode was used. Standard reference calomel electrode is connected to a positive terminal of the same source and resistance was measured between calomel rod and positive rod of the specimen. Current and resistance readings were noted until the visible cracks were formed. It was nearly about 45 days, from the day of commencement of experiment. Fig -3 shows the failed specimens for NAC.
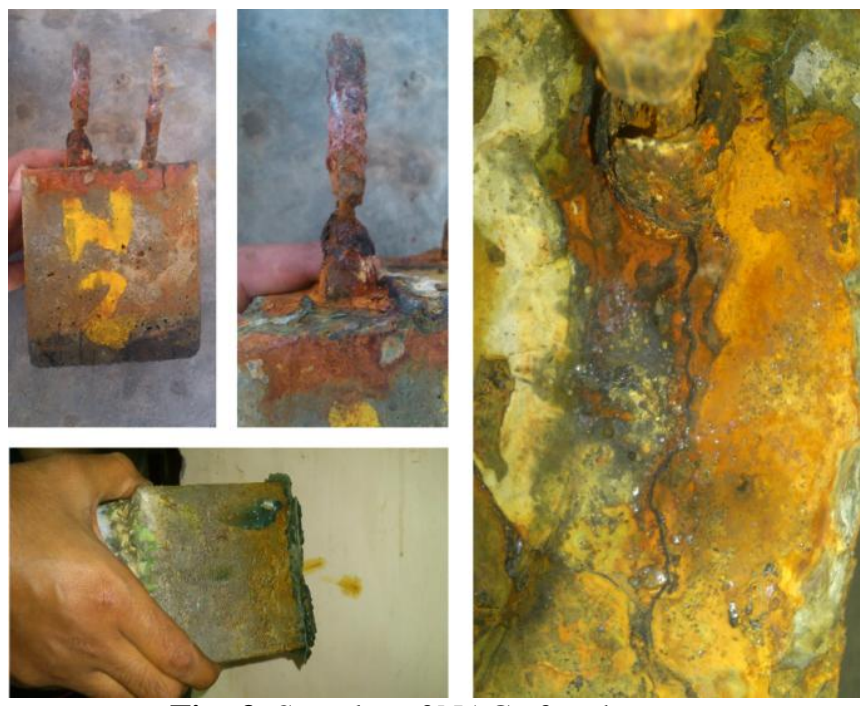

Fig -3: Samples of NAC after the test

\subsection{Linear Polarization Resistance Test (LPR)}

Each specimen had two embedded bars of $300 \mathrm{~mm}$ length and $10 \mathrm{~mm}$ dia. The steel bars were cleaned before placement for corrosion test. The specimens were exposed to an aqueous solution of $5 \% \mathrm{NaOH}$ solution to assess all the specimens. The concrete cubes were casted as a part of 
five different sets (15 samples). Each specimen consists of two $10 \mathrm{~mm}$ diameter reinforced bars with a length of $200 \mathrm{~mm}$ embedded inside at a clear cover of $45 \mathrm{~mm}$ from bottom. The specimens were cured for 28 days in water and air-dried for one day. Connections should be given such that one rod is connected to positive terminal and the other to negative terminal as shown in Fig -4 and a constant voltage of $12 \mathrm{~V}$ DC supply is provided

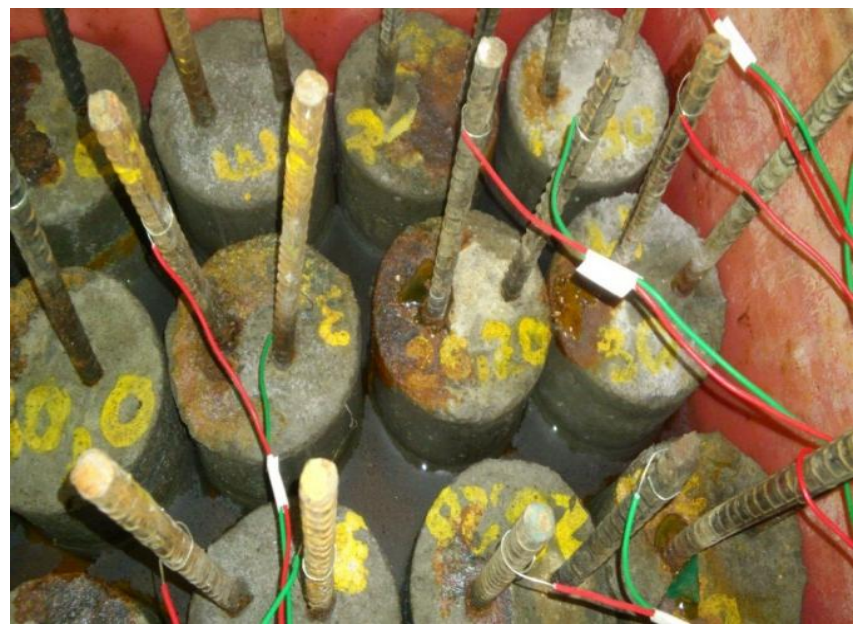

Fig -4: Connections of LPR test

A constant voltage of $12 \mathrm{~V}$ DC supply is provided and change in the electrolytic resistance $\left(R_{e}\right)$, which has correlation with the concrete resistivity $(\rho)$; and the variation in the Resistance of charge transfer $\left(R_{c t}\right)$, which has correlation with the corrosion current density $\left(i_{\text {corr }}\right)$ of reinforcement is measured. The evaluation of parameters $R_{e}$ and $R_{c t}$ was accomplished by constructing standard galvanic potential cell with a reference rod as calomel rod and electrolyte as $\mathrm{NaCl}$ solution. The samples after the LPR test have been shown in Fig -5.

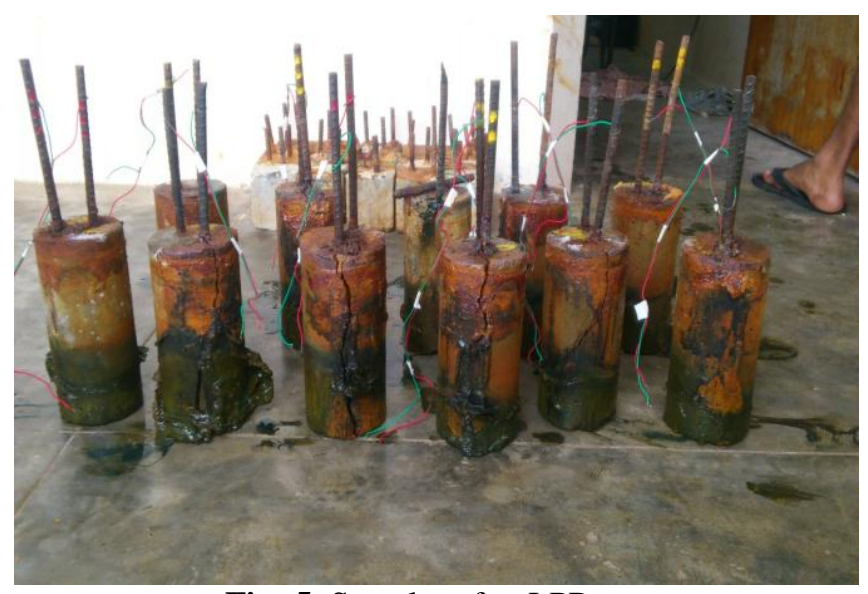

Fig -5: Samples after LPR test

\subsection{Impressed Voltage Test}

The setup for this test included a DC power source of $24 \mathrm{~V}$ supply, test specimens with steel bar embedded inside which acts as anode and a plastic tub containing a $5 \%-\mathrm{NaCl}$ solution as electrolyte, stainless steel rod as cathode and a multi meter. The impressed voltage test setup is shown in Fig -6 .

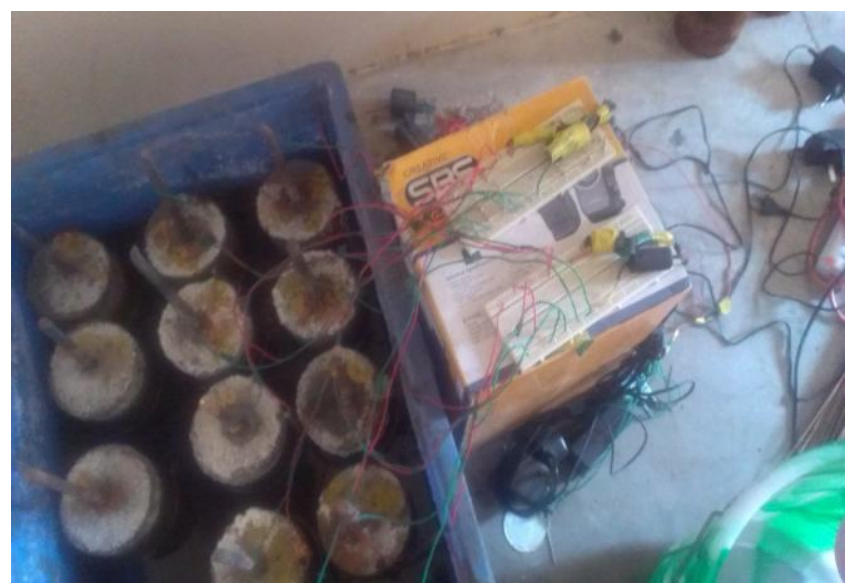

Fig -6: Samples for Impressed Voltage test

The steel reinforcement (the working electrode) of the reinforced concrete specimen was connected to the positive terminal and the steel rods (the counter electrodes) were connected to the negative terminal of the DC power source applying $24 \mathrm{~V}$. The amount of voltage passing is regularly checked. The specimens were daily taken out from solution and keenly investigated for visual cracks.

\subsection{Weight Loss Test}

Weight loss test enables us to find out how much weight of rods has been corroded during experiment. It can be obtaining by taking the difference of initial and final weights of the rods used in the specimen. Initially the rods were marked to identify and then initial weights were taken. After the completion of experiments, the rods were taken out from the specimens by placing them under UTM. The rods were initially cleaned to remove the binded matrix around it. Then the rods were dipped in HCL solution to clean the rods from settled dust and corroded layers around it. Final weights were taken for calculating corrosion.

\section{RESULTS AND DISCUSSIONS}

\subsection{Salt Ponding Test}

The corrosion products lead to higher internal tensile stresses in the hardened concrete. Being exposed to these stresses the hardened concrete cracks and splits off. As per test results the $i_{\text {corr }}$ and corrosion rate values of NAC are less comparison to RAC but comparing with $0 \%, 10 \%, 20 \%$ and $30 \%$. 20\% fly ash is having less corrosion rate value. And approximately equal to NAC. The Chart -1 shows the current vs days, comparing NAC to RAC. 


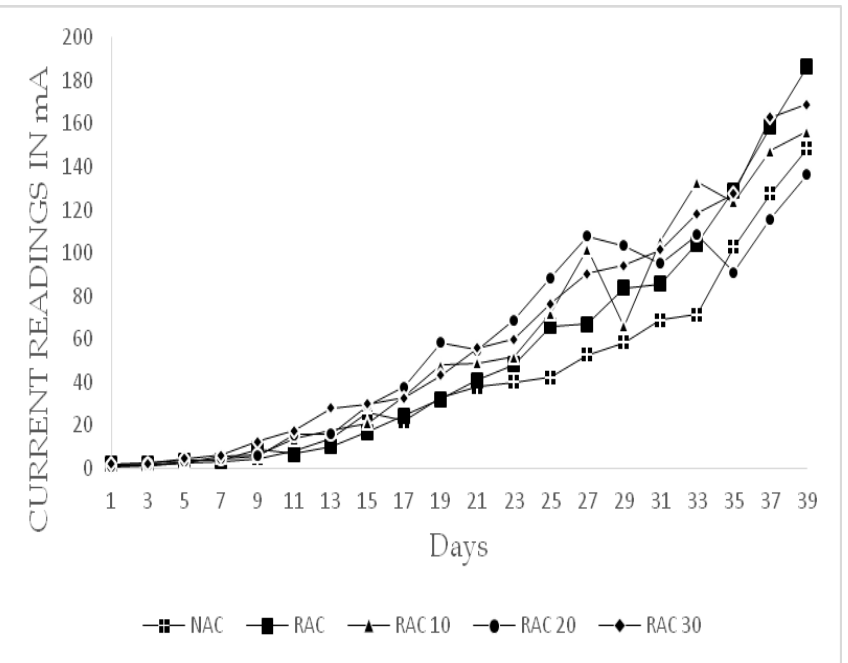

Chart -1: Current values from salt ponding test

The Table -1 shows the final corrosion rate values of salt ponding test. From the table it is shown that RAC 20 is having less corrosion rate value and is almost equal to NAC. From the above graph in 40 days of ponding test the current reading of RAC 20 is having less current value than RAC, RAC10 and RAC30. As the current value is less the value of resistance is high, as resistance is high the corrosion rate value decreases. So as in salt ponding test the RAC20 is most preferable and almost equal to NAC in corrosion rate.

Table -1: Corrosion rate values

\begin{tabular}{|l|l|l|l|l|l|}
\hline Description & NAC & RAC & $\begin{array}{l}\text { RAC } \\
10\end{array}$ & $\begin{array}{l}\text { RAC } \\
20\end{array}$ & $\begin{array}{l}\text { RAC } \\
30\end{array}$ \\
\hline$i_{\text {corr }}$ & 0.924 & 5.7 & 1.525 & 0.917 & 1.055 \\
\hline $\begin{array}{l}\text { Corrosion } \\
\text { rate } * 10^{-3}\end{array}$ & 10.715 & 66.12 & 17.65 & 10.625 & 12.235 \\
\hline
\end{tabular}

\subsection{Linear Polarization Resistance Test}

Electrochemical properties of concrete-steel systems with a 30-days exposure are represented in the Table -2. It shows that the RAC $100 \%$ has minimum values of Resistance, while the RAC 10 reaches the maximum. As the value of resistance is low the corrosion rate is will be high. Chart -2 shows that the RAC10 is having less corrosion rate and approximately equal to NAC.

Table -2: Corrosion rate values from LPR test

\begin{tabular}{|l|l|l|l|l|l|}
\hline $\begin{array}{l}\text { Descriptio } \\
\mathrm{n}\end{array}$ & NAC & $\begin{array}{l}\text { RA } \\
\mathrm{C}\end{array}$ & RAC10 & RAC20 & RAC30 \\
\hline$i_{\text {corr }}$ & 11.84 & 30.7 & 12.87 & 22.56 & 44.57 \\
\hline $\begin{array}{l}\text { Corrosion } \\
\text { rate } * 10^{-3}\end{array}$ & 137 & 356 & 149 & 261.5 & 514.5 \\
\hline
\end{tabular}

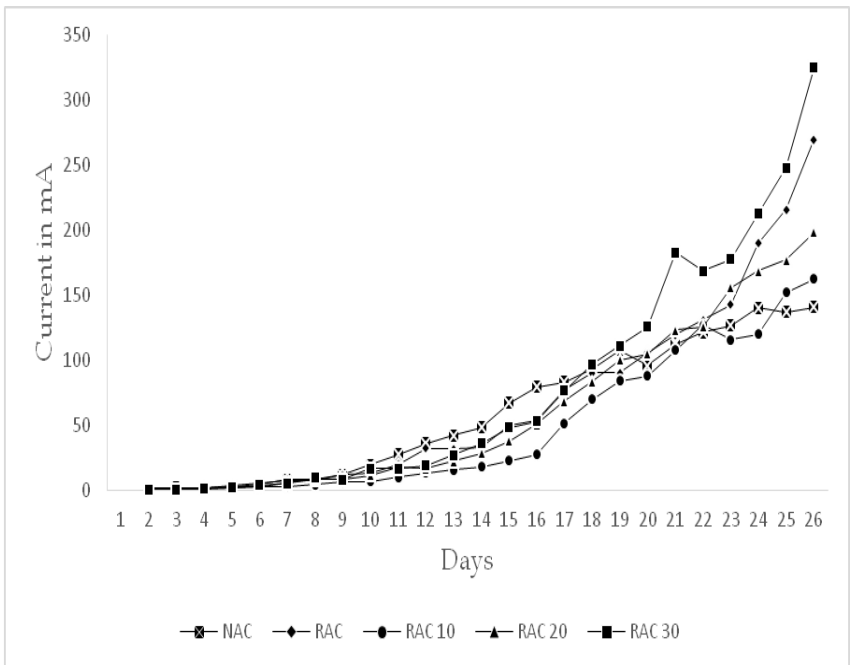

Chart -2: Current values from LPR test

\subsection{Impressed Voltage Test}

After the tests it was observed that the mechanical properties of the concretes and the corrosion performances of the steel embedded in the concrete changed with different cement types, dosages, FA amounts used as the replacements for the cement and the curing time. According to a general assessment of the results, an increase in the dosage, the curing time and the FA amount used to replace the cement caused an increase in the damage occurrence time of the reinforced concrete specimens. The damage occurrence time of RAC10 is more compare to other RAC's and even RAC10 the damage occurrence time is a little more than NA and these times are tabled and shown in the Table -3 . Consequently, the corrosion of the steel embedded in the concrete depends significantly on the cement type, the cement dosage and the curing time. To combat the corrosion of the steel reinforcement in the concrete, the permeability of concrete by water and hazardous ions has to be prevented. This is possible by producing an impermeable concrete. For this reason, impermeable and high-quality concretes have to be produced by using various mineral admixtures such as FA.

Table -2: Damage occurrence time

\begin{tabular}{|l|l|l|}
\hline S. No. & Description & $\begin{array}{l}\text { Damage occurrence } \\
\text { time days }\end{array}$ \\
\hline 1 & NAC & 18 \\
\hline 2 & RAC & 15 \\
\hline 3 & RAC10 & 19 \\
\hline 4 & RAC20 & 16 \\
\hline 5 & RAC30 & 14 \\
\hline
\end{tabular}

\section{CONCLUSIONS}

The following conclusions are drawn from the experimental study:

- Water absorption of recycled aggregate is found to be higher than that of natural aggregate. Specific gravity of recycled aggregates is found to be lower than that of natural aggregates. Bulk density, 
flakiness and elongation index, and fineness modulus value of recycled are also lower than natural aggregate. However, by replacing cement with $10 \%$ of fly ash, the compressive strength of RAC are closer to NAC. Hence, it is preferable to use $10 \%$ fly ash as replacement of cement for better compressive strength.

- From Salt Ponding test, it is noted that the corrosion rate of RAC20 is low and is almost equal to NAC. It is clear from these results that the addition of fly ash in RAC improves the durability characteristics. From the results of Salt Ponding test, it is observed that the rate of corrosion of RAC after 40 days is almost equal to NAC.

- $\quad$ From LPR test, it is observed that the corrosion rate of RAC10 is low and is almost equal to NAC. The same trend is seen in current measurement also. From LPR test, corrosion value of RAC10 is lower and almost equal the NAC which denotes $10 \%$ replacement of fly ash. The current graph of LPR Test is drawn and RAC10 is having less current value and equals to NAC. By LPR Test RAC10 is good to replace NAC.

- In Impressed Voltage Test the Damage Occurrence Time of RAC10 is high and approximately equals to NAC. By Impressed Voltage Test RAC10 is good to replace NAC. From the result of Impressed Voltage test, the damage occurrence time of RAC10 is approximately 19 days which is very close to damage occurrence time of NAC (NAC damage occurrence 18 days).

It is very clear from these above studies that the fly ash greatly influence the durability of concrete. From this limited study, it is proposed to use fly ash in replacement of cement in the range of $10 \%$ to $20 \%$ in order to achieve better RAC with strength and durability characteristics as that of NAC.

\section{REFERENCES}

[1]. Berndt M.L., "Properties of sustainable concrete containing fly ash, slag and recycled concrete aggregate", Construction and Building Materials Journal, vol.23, 2009, pp.2606-2613.

[2]. C.C. Yang, L.C. Wang," The diffusion characteristic of concrete with mineral admixtures between salt ponding test and accelerated chloride migration test", Materials Chemistry and Physics, vol.85, 2004, pp.266-272

[3]. Chakradhara Rao. M, Bhattacharyya. S. K and Barai. S. V., "Microstructure of recycled aggregate," Journal of structural engineering, Vol.38, No.1, 2011, pp.75-83

[4]. Jian Yang, Qiang Du, Yiwang Bao, "Concrete with recycled concrete aggregate and crushed clay bricks", Construction and Building Material, vol.25, 2011, pp.19351945

[5]. Limbachiya M c., Koulouris A., Robert J J., and Fried A N., Kingston University, UK., "Performance Of Recycled Aggregate", Concrete Rilem Publication, 2004.
[6]. Parekh D.N and Dr. Modhera C.D., "Assessment of Recycled Aggregate Concrete" Journal of Engineering Research and Studies, Vol.2, No.1, 2011, pp.1-9.

[7]. Yong, P.C and Teo, D.C.L., "Utilization of recycled aggregate as coarse aggregate in concrete" Journal of civil engineering, vol. 1, No. 1, 2009. 